\section{The reversal of classical contrast in temperature perception}

\author{
HOWARD E. EGETH, Johns Hopkins \\ University, Baltimore, Md. 21218, and \\ ARTHUR S. KAMLET ${ }^{1}$ and RUSSELL $A$. \\ $B E L L$, U.S. Army Human Engineering \\ Laboratories, Aberdeen Proving Ground, \\ Md. 21005
}

Perceptual assimilation was demonstrated with some sets of thermal stimuli. This result is at variance with previous research, which has consistently yielded contrast effects.

It has been known for centuries that the perception of temperature depends on the state of adaptation of the skin as well as on the thermal properties of the stimulating object. Consider, for example, the following paradigm, not unlike the classic three-jar experiment described by John Locke in his 1690 Essay Concerning Human Understanding. An O places his left hand on a plate that has been heated to $35^{\circ} \mathrm{C}$, and places his right hand on a similar plate at $32^{\circ} \mathrm{C}$. After about a minute, the $\mathrm{O}$ moves his hands to two other plates, both at $40^{\circ} \mathrm{C}$. Which one of these two latter readers will correctly predict that the right-hand plate will feel warmer, even though both were at the same objective temperature. What this experiment demonstrates is the phenomenon of contrast. Essentially, contrast refers to the enhancement of the subjective intensity of a stimulus when it is compared with, or follows, a relatively weak stimulus (or to its diminution when compared with a relatively strong stimulus). The purpose of this report is to follow up some pilot thermal sensitivity may be more complex than consideration of the preceding specifically, it is our purpose to show that men. plates will feel warmer to the $O$ ? Most studies that indicated that the study of experiment would indicate. More

under appropriate conditions it is possible to obtain the reversal of classical contrast, i.e., assimilation. Thus, in the situation described above, if the $\mathrm{O}$ had judged that the left-hand test plate was the warmer of the two we would say that this represented assimilation. To the present writers knowledge, there is no previous report of assimilation in the literature on temperature perception.

\section{SUBJECTS}

The Ss were 480 U.S. Army enlisted

\section{PROCEDURE}

The stimuli were four aluminum plates, each of which rested on an electric heating pad. The temperatures of the plates were controlled by the voltages applied to the pads. The plates were arranged in a horizontal line in front of the $S$; the two on the left served as the adaptation stimuli, while the two on the right were the test stimuli. The $S$ placed his hands, palms down, on the adaptation pads. At the end of the adaptation period, he quickly moved his hands to the test plates and immediately judged the temperature of one test plate relative to the other. (It should be emphasized that the two test plates were always objectively equal to one another in temperature.) A 9-point response scale was used, ranging from "very much warmer" through "not any different" to "very much cooler." Within each condition, half of the Ss judged the right test pad relative to the left and the other half judged the left relative to the right. The left or right placement of the warmer of the two adaptation pads was also balanced within conditions.

Ten combinations of adaptation and test temperatures, arbitrarily selected, were combined factorially with three adaptation times $(10 \mathrm{sec}, 1 \mathrm{~min}$, and $6 \mathrm{~min}$ ), resulting

Table I

Assimilation and Contrast for Each Combination of Adaptation and Test Temperature ( $\mathrm{C}$ ) at Each Adaptation Duration

\begin{tabular}{|c|c|c|c|c|c|c|}
\hline \multirow{2}{*}{$\frac{\text { Combination }}{1}$} & \multicolumn{2}{|c|}{ Adaptation } & \multirow{2}{*}{$\frac{\text { Test }}{21}$} & \multirow{2}{*}{$\frac{10 \mathrm{Sec}}{1.3^{*}}$} & \multirow{2}{*}{$\frac{60 \mathrm{Sec}}{6}$} & \multirow{2}{*}{$\frac{360 \mathrm{Sec}}{.2}$} \\
\hline & 25 & 29 & & & & \\
\hline 2 & 29 & 40 & 21 & $-1.2^{*}$ & -.3 & -.6 \\
\hline 3 & 35 & 40 & 21 & $-1.4 * *$ & -.8 & -.8 \\
\hline 4 & 21 & 25 & 29 & $1.1^{* *}$ & .4 & $1.0^{*}$ \\
\hline 5 & 32 & 35 & 29 & $.8^{*}$ & .5 & .7 \\
\hline 6 & 29 & 32 & 35 & .7 & $1.1^{*}$ & $9^{*}$ \\
\hline 7 & 37 & 40 & 35 & .9 & $1.1^{* *}$ & $.8^{*}$ \\
\hline 8 & 21 & 29 & 40 & $-1.9 *$ & $-1.4^{* *}$ & -.7 \\
\hline 9 & 21 & 35 & 40 & $-2.1^{* *}$ & .1 & -.2 \\
\hline 10 & 35 & 37 & 40 & .9 & $1.1^{*}$ & .56 \\
\hline
\end{tabular}

Note-Negative numbers indicate assimilation

$* \quad p<.05 ; * * p<.01$ in 30 experimental conditions (see Table 1). Sixteen different $\mathrm{Ss}$ were run in each condition, and each $S$ rendered a single judgment.

\section{RESULTS}

Each response on the 9-point verbal scale was assigned a number to indicate directly the degree of contrast, with negative numbers indicating assimilation. The results in Table 1 show the mean amount of assimilation or contrast for each of the 30 experimental conditions. These means were subjected to t tests (two-tailed), and the ones that were found to differ significantly from zero are indicated by asterisks. As an additional check on the reliability of the phenomenon of assimilation, another $32 \mathrm{Ss}$ were run in Condition 9, with a 10 -sec adaptation period. Of these $32 \mathrm{Ss}, 29$ gave assimilation responses, and 3 gave neutral responses.

It appears that Combinations 2, 3, 8 . and 9 differ from the others in that these four combinations tended to produce assimilation rather than contrast. Furthermore, assimilation was more pronounced at the $10 \mathrm{sec}$ than at the longer adaptation times. The one factor that seemed to determine whether assimilation or contrast would obtain was the overall range of temperatures spanned by the stimuli. Assimilation was observed in the four conditions that had a $19^{\circ}$ range but not any of the other conditions. none of which had a range greater than $8^{\circ}$.

\section{CONCLUSIONS}

The paradigm used in the present experiments required of each $S$ a single, immediate, comparative response following the adaptation period. Thus, it would seem that we have demonstrated perceptual assimilation rather than the kind of complex, memory-dependent judgmental bias that has been found in more complex experimental tasks (e.g., Holland \& Lockhead, 1968). This demonstration of perceptual assimilation was surprising as it was quite at variance with previous studies of adaptation and context in temperature perception (e.g., Woodworth \& Schlosberg, 1954, Chap. 10). The present authors are not offering an explantion for this phenomenon; rather, they are hopeful that these data will stimulate further investigation.

\section{REFERENCES}

HOLLAND, M. K., \& LOCKHEAD, G. R. Sequential effects in absolute judgments of loudness. Perception \& Psychophysics, 1968, 3, 409-414.

WOODWORTH, R. S., \& SCHLOSBERG, H.

Experimental psychology. New York: Henry Holt, 1954.

NOTE

1. Now at Bell Telephone Laboratories. Whippany, New Jersey. 